\title{
Perjuangan Masyarakat Adat untuk Keadilan Ekologis di Teluk Benoa, Bali
}

\author{
Slamet Subekti \\ Departemen Sejarah Fakultas Ilmu Budaya Universitas Diponegoro \\ Jl. Prof. Soedarto, SH. Tembalang Semarang 50275 \\ Email : slamet.subekti@live.undip.ac.id
}

\begin{abstract}
Environmental tragedy overshadows efforts to seize coastal space (Coastal and Ocean Grabbing) in part from 1,373 ha. for the Benoa Bay reclamation project in South Bali. So far, Benoa Bay has become a livelihood for fishermen and marine tourism practitioners. This water area with intertidal tides allows flushing to maintain sea water quality, in addition to the 100 ha of "Ngurah Rai" mangrove forest. which regulates hydro-orology around Denpasar. Public reasoning was disturbed when the investors of PT TWBI facilitated by the State through the Presidential Regulation, the Ministerial Decree KP and the Bali Governor's Decree planned to build 12 islands by sinking over 700 ha of water. for established hotels, villas, offices, educational facilities, sports complexes, trade, botanical gardens, apartments and floating villas. The controversy took place when the results of an AMDAL study from LPPM Udayana University stated that the Benoa Bay area was not socio-culturally suitable for reclamation, but investors sought to continue the reclamation by cooperating with a number of universities from outside Bali to conduct a comparative AMDAL study. Responding to the plan, the indigenous people through Paruman Pakraman stated their attitude to reject the reclamation of Benoa Bay by considering environmental sustainability and the preservation of customary-cultural areas. The reclamation issue of Benoa Bay in its development has not only been an environmental issue, but has penetrated into the realm of local politics. When the Bali Pilgub, Denpasar Pilwakot and Badung Pilbup and even the election of Bandesa (traditional village officials) conditioned all candidates to make an integrity pact rejecting the reclamation of Benoa Bay, including candidates who had been known to be pro-reclamation. After twice (2014-2018) the location permit was declared not meeting the AMDAL study, now investors have obtained a new permit (2018-2020) from the KKP to continue the struggle over the Benoa Bay living space. The ForBALI movement, which is the mandate of Pasubayan Pakraman, is preparing a new round of struggle for environmental justice in Benoa Bay. ForBALI's agenda going forward, first: push the results of the AMDAL study to be socio-culturally inappropriate. Second, submit a review of Perpres No. 51/2014 which is the "culprit" of the Benoa Bay reclamation discourse. Third, encourage the cancellation of Perpres No. 51/2014 to end the Benoa Bay reclamation polemic.
\end{abstract}

Keywords: indigenous peoples, ecological justice, reclamation, Benoa Bay, Bali 


\section{Pendahuluan}

Berbicara tentang perjuangan masyarakat untuk keadilan ekologis di Teluk Benoa membawa perhatian kita kepada sejumlah tokoh, antara lain Koordinator ForBALI I Wayan "Gendo" Suardana bersama pegiat WALHI Bali, musisi Jerinx dan band "SID", akademisi Dr. L.G. Saraswati Putri (UI) dan Agung Wardana Ph.D (UGM) serta ribuan masyarakat adat di Bali dan sekitarnya, LSM nasional maupun internasional dan simpatisannya. Cerita besar makalah ini tentang isu lingkungan hidup, dengan mengusung tema keadilan ekologis yang secara khusus fokus pada kasus reklamasi Teluk Benoa. Relevansi isu lingkungan hidup ini karena Indonesia saat ini masih dalam kondisi darurat ekologis. Hal itu ditandai dengan penguasaan ruang wilayah darat maupun laut Indonesia tetap didominasi kepentingan industri ekstraktif.

Dominasi penguasan ruang dan praktik buruk pengelolaan lingkungan hidup ini yang mengakibatkan Indonesia masih berada dalam kondisi darurat ekologis. ${ }^{1}$ Fakta darurat ekologis ini dapat dilihat dari (1) kuantitas bencana ekologis yang masih tinggi; (2) masih tingginya kuantitas konflik sumber daya alam yang tidak diikuti oleh kebijakan penyelesaian konflik yang baik; (3) kondisi pencemaran di daerah aliran sungai dan sumber air yang semakin hari semakin parah; (4) kebijakan pengelolaan wilayah pesisir dan pulau kecil yang masih berpihak pada kepentingan investasi, contoh konkritnya bisa dilihat dari kebijakan reklamasi; dan (5) kondisi penegakan hukum yang masih memperlihatkan corak keberpihakannya kepada pemodal dan cenderung mengkambinghitamkan rakyat.

Sementara untuk kebijakan regulasi, penerbitan peraturan perundang-undangan yang baik diturunkan dalam bentuk peraturan teknis yang ambigu. Aktor negara masih melakukan kebijakan bermuka dua, di satu sisi secara populis menyatakan keberpihakannya kepada rakyat, namun dalam implementasinya masih dominan berpihak kepada kepentingan investasi. Adapun korporasi, masih mempertahankan watak ekspansif dan serakahnya, dimana beberapa kebijakan negara yang berpihak kepada keadilan ekologis dilawan dengan berbagai upaya sistematis, baik melalui jalur hukum; melakukan intervensi politik secara masif melalui parlemen; dan mendompleng kebijakan negara untuk menyelamatkan kepentingannya. Pada lain pihak, rakyat secara perlahan mulai sadar dengan hak konstitusionalnya dan mempergunakannya untuk melawan kebijakan yang abai terhadap aspek lingkungan dan hak asasi manusia.

Sehubungan dengan isu lingkungan hidup tersebut, tema keadilan ekologis perlu mendapatkan perhatian yang mendesak. Keadilan ekologis sebagai sebuah hak untuk mendapatkan keadilan antar generasi yang memperhatikan prinsip keadilan gender, prinsip keselamatan rakyat, keberlanjutan jasa pelayanan alam dan perlindungan produktivitas rakyat. Pada prinsipnya semua generasi baik sekarang maupun mendatang, laki-laki maupun perempuan berhak terselamatkan dari ancaman dampak dan krisis, serta penghancuran lingkungan hidup dan sumber-sumber kehidupan rakyat. Dengan demikian, keadilan ekologis merupakan sebuah perjuangan menuju keseimbangan alam dan manusia tanpa penguasaan untuk kepentingan intra dan antar generasi.

Pertanyaan kunci dalam konteks keadilan ekologis ini adalah siapa aktor perusak lingkungan hidup? Menurut analisis WALHI, bahwa aktor utama perusak lingkungan hidup adalah korporasi terutama yang berinvestasi di sektor tambang dan perkebunan. Aktor kedua adalah pemerintah dan aktor ketiga adalah kombinasi antara korporasi dan pemerintah, serta aktor terakhir adalah dari masyarakat. Temuan ini memperkuat masyarakat sipil untuk terus mendesak tanggungjawab korporasi terhadap kejahatan lingkungan yang telah dilakukan. Fenomena kolaborasi antara korporasi dan pengurus negara ini memperkuat analisis sebelumnya bahwa persoalan lingkungan

${ }^{1}$ WALHI Tinjauan Lingkungan Hidup 2018.Masa Depan Keadilan Ekologis di Tahun Politik. 
tidak dapat dilepaskan dari keterikatan atau konsolidasi yang semakin menguat antara kepentingan modal dengan kekuasaan (tali temali ekonomi-politik kekuasaan). Sedangkan masyarakat sebagai pelaku ditemukan pada tambang-tambang inkonvensional dengan tingkat resiko yang tinggi, dan proses pembiaran yang dilakukan oleh pemerintah tanpa memberikan alternatif sumber penghidupan yang lain. Hal ini mematahkan stigma bahwa aktor perusak lingkungan adalah orang miskin, serta kemiskinan sebagai penyebab dari kerusakan lingkungan. ${ }^{2}$

Sasaran protes yang dilakukan oleh masyarakat sipil yang sebagian besar dilakukan oleh LSM/NGO dan masyarakat adalah pemerintah, hal ini terkait dengan berbagai kebijakan yang dikeluarkan pengurus negara baik di tingkat nasional maupun daerah. Desakan perubahan menjadi agenda utama yang terus didorong oleh aksi protes masyarakat. Hal ini menunjukkan relasi antara kebijakan yang dikeluarkan negara dengan persoalan lingkungan yang dihadapi oleh masyarakat. Kebijakan justru menjadi legitimasi bagi korporasi untuk melakukan kejatahan dengan "stempel" dari pemerintah melalui perundang-undangan, regulasi dan pemberian ijin.

Sasaran protes berikutnya adalah korporasi atau perusahaan di wilayah konsesinya, yang menjadi sasaran protes warga. Ini menunjukkan bahwa sesungguhnya masyarakat mulai "melek" dengan hak-haknya dan juga mulai mengerti dengan hukum, dan mulai paham dengan akar persoalan yang dialami, serta mengetahui siapa aktor dan kepentingannya. Hal ini tidak dapat dilepaskan dari kerja-kerja yang dilakukan oleh masyarakat sipil untuk terus-menerus melakukan pendidikan kritis kepada masyarakat melalui pengorganisasian di kampung-kampung.

Ungkapan protes terhadap korporasi PT TWBIberikut ini merupakan ungkapan kesadaran kritis pejuang keadilan ekologis seperti disuarakan oleh koordinator ForBALI I Wayan "Gendo" Suardana:

"Kawan2, sesuatu yg menjemukan dan melelahkan adalah rutinitas. Apapun yang terlalu sering kita lakukan akan membuat kita bosan. Demikian halnya dengan aksi @forbali13 Tolak reklamasi Teluk Benoa.

Bayangkan selama 6 tahun, rata2 setiap bulan kita menggelar demo. 1 th $=12$ bulan, berarti selama 6 th kita sudah menggelar aksi rutin sebanyak $72 x$ demo. Itu yg rutin. Belum lagi kalo dihitung, aksi-aksi sporadis seperti aksi massa deklarasi desa adat, deklarasi STT, deklarasi banjar, deklarasi STT atau deklarasi Forum pemuda, makanya jumlah deklarasi ini berkisar pada 45x. Belum lagi dihitung dengan aksi2 pemasangan baliho, pentas musik, konser mini, pagelaran seni dll. Belum termasuk diskusi-diskusi publik dll. Total aksi2 tersebut mencapi ratusan kali total melebihi angka 200x.

Itu yg sifatnya aksi2. Bagaimana dengan keseharian? Selama 6 tahun energi kita terkuras menyebarluaskan perlawanan ini. Menyebarluaskan sikap dan pemikiran kita, baik di medsos ataupun di setiap laku kita. Nah melelahkan dan membosankan, bukan?!

Saya yakin banyak yag bosan dan jenuh tapi memang itulah ujiannya. Sekali anda jenuh saat itu investor akan tertawa, karena sekarang yg mereka tunggu adalah kejenuhan kita. Kebosanan kita. Kejemuan kita sehingga kita bubar dengan sendirinya. Mereka sekarang tidak represif tapi memilih duduk diam menunggu kelengahan kita sementara bidak2 catur

${ }^{2}$ WALHI Februari 2013. Perampasan Lahan dan Krisis Pangan. 
dgn logistik yg melimpah ruah sudah siap bekerja. Sekali saja kita lengah, saat itu bidak caturnya akan bekerja.

Pertanyaannya apakah kita akan memberikan kesempatan bidak caturnya melangkah? Kalau Saya akan menjawab; "Tidak! Saya tidak mau. Saya akan terus melawan." Yang setuju dgn sikap Saya mari bergabung pada aksi Minggu 23 Juni 2019, pukul 14.00 wita di Parkir Timur Lapangan Niti Mandala."

[Wayan Gendo Suardana, “Panggilan Aksi BTR”, 16 Juni 2019]

Bentuk kesadaran kritis tersebut menunjukkan pemahaman masyarakat terhadap perkembangan terkini Kapitalisme dengan kemampuannya menstranfor-masikan diri guna merespon krisis dan potensi krisis yang disebabkan oleh kontradiksi internalnya di era Neoliberal ini. Krisis lingkungan dan permasalahan sosial yang ditimbulkan kapitalisme dengan cepat diubah menjadi peluang baru bagi perluasan akumulasi modal demi mempertahankan keberlanjutannya. Hasilnya adalah kemunculan kaum kapitalis yang menampilkan diri berwajah manusiawi dan penyelamat lingkungan sebagai strategi kontemporer untuk meredam perlawanan sosial. Strategi ini sekaligus guna mengaburkan batas-batas dikotomi antara kedermawanan (charity) dan mengejar keuntungan (profit-making), juga privat dan publik, sehingga operasi kapitalisme yang selama ini terbatas pada panah privat membuka ruang-ruang manuver baru pada semua lini kehidupan. ${ }^{4}$

\section{Wacana Reklamasi}

Polemik terkait upaya reklamasi perairan Teluk Benoa berawal dari serangkaian kebijakan yang dikeluarkan Gubernur Bali, mulai dari penerbitan SK Nomor 2138/02-CL/HK/2012 (tentang Rencana Pemanfaatan dan Pengembangan Kawasan Perairan Teluk Benoa) secara diam-diam pada 26 Desember 2012. SK tersebut mendapat penolakan dari masyarakat baik dari individu, LSM, Akademisi dan Anggota DPRD, selanjutnya sampai menerbitkan Surat Keputusan Gubernur Bali Nomor 1727/01-B/HK/2013 tentang Izin Studi Kelayakan Rencana Pemanfaatan, Pengembangan dan Pengelolaan Wilayah Perairan Teluk Benoa (sering disebut sebagai SK Reklamasi Jilid 2) sekaligus mencabut SK Gubernur Bali Nomor 2138/02-C/HK/2012 (sering disebut SK Reklamasi jilid 1$)^{5}$

Hal menarik dari keputusan Gubernur ini ketika "dipaksa" untuk menempatkan posisi kedua SK itu dalam aras argumentasi Gubernur yang sedari awal menghindari penyebutan SK reklamasi, baik pada SK Reklamasi jilid 1 maupun SK jilid 2. Sebagaimana diketahui secara umum, pada SK Gubernur Bali Nomor 2138/02-C/HK/2012 Izin dan Hak Pemanfaatan, Pengembangan dan Pengelolaan Wilayah Perairan Teluk Benoa (SK yang pertama), Gubernur Bali sangat menghindari

${ }^{3}$ https://www.facebook.com/gendo.suardana?

${ }^{4}$ Wardana, Agung. "Neoliberalisasi Kawasan Perairan Teluk Benoa: Sebuah Catatan Kritis atas Praksis Perlawanan di Bali" dalam Ekologi Politis Air: Akses, Eksklusi, dan Resistensi. WacanaJurnal Transformasi Sosial Nomor 35/Tahun XIX/2017.

${ }^{5}$ Wayan "Gendo" Suardana. "Menguak Misteri SK Reklamasi Jilid 2". 
penyebutan SK pelaksanaan reklamasi atau setidak-tidaknya menyebut SK Reklamasi. Beliau hanya menyebut bahwa SK 2138/02-C/HK/2012 sebagai SK kajian lanjutan dan baru pada dialog terbuka (3 agustus 2013) Gubernur secara tegas menyebutkan bahwa SK tersebut sebagai SK Lokasi Reklamasi (lebih sering disebut sebagai SK ijin prinsip).

Walaupun pada akhirnya di rapat terbuka itu pula pihak Gubernur Bali dan SKPD terkait tidak mampu mempertanggungjawabkan argumentasinya kecuali secara diam-diam mengakui bahwa SK tersebut sejatinya adalah SK pelaksanaan reklamasi.Sejatinya SK Gubernur Bali Nomor 1727/01-B/HK/2013 tentang Izin Studi Kelayakan Rencana Pemanfaatan, Pengembangan dan Pengelolaan Wilayah Perairan Teluk Benoa adalah kegiatan perencanaan reklamasi dan termasuk dalam ruang lingkup pengaturan Perpres 12 tahun 2012. SK tersebut tidak dapat dikategorikan sebagai izin penelitian pengembangan sebagaimana yang diatur dalam bab VII UU 27 tahun 2007 tentang Pengelolaan Wilayah Pesisir dan Pulau-Pulau Kecil.

SK tersebut termasuk sebagai kegiatan reklamasi dan obyeknya adalah kawasan Konservasi Perairan Teluk Benoa yang terlarang di reklamasi (vide perpres no. 45 tahun 2011 dan Perpres no 122 tahun 2012) maka SK Gubernur tersebut adalah KTUN.Itu bertentangan dengan peraturan perundangan baik bertentangan dengan UU no 26 tahun 2007 jo. Perpres 45 tahun 2012 dan UU no 27 tahun 2007 jo. Perpres no 122 tahun 2012, oleh karenanya hal tersebut dapat pula dikategorikan sebagai perbuatan melawan hukum oleh penguasa. Perbuatan melawan hukum telah dilakukan oleh Gubernur Bali dalam penerbitan SK Gubernur Bali Nomor 1727/01-B/HK/2013 tentang Izin Studi Kelayakan Rencana Pemanfaatan, Pengembangan dan Pengelolaan Wilayah Perairan Teluk Benoa mengandung konsekuensi pidana tata ruang sebagaimana yang diatur dan ditentukan oleh UU no 26 tahun 2007 tentang penataan ruang.

Strukturasi sebagaimana dikemukakan oleh Anthony Giddens dapat digunakan untuk memahami hubungan "negara" dengan "masyarakat", karena lebih mampu membuka segi-segi yang dilupakan oleh pendekatan Pluralisme maupun Marxisme. Hubungan antara struktur dan agensi dipandang secara berat sebelah, dengan penekanan pada struktur atau agensi. Kosekuensinya, agensi menjadi "korban struktur" dalam strukturalisme (Marxisme) atau struktur mengalami "imperialisme subjek" dalam intensionalisme (Pluralisme). Sebagaimana dikemukakan Giddens, yang dimaksud dengan "struktur" adalah "rules and resources" yang dipakai pada kesempatan produksi dan reproduksi sistem sosial. ${ }^{6}$ Sedangkan "agensi" adalah terjemahan langsung dari kata Inggris "agency" yang dipahami sebagai individu, sejauh ia sebagai "perpetrator". ${ }^{7}$ Segala sesuatu tidak mungkin terjadi lewat intervensi si individu.

Giddens dipandang sebagai orang pertama yang berhasil menghasilkan teori yang menghubungkan struktur dan agensi. Teorinya disebut "teori strukturasi". Dalam teori ini, struktur dan agensi tidak dipandang sebagai dua hal, karena jika demikian akan muncul dualisme strukturagensi. Menurut Giddnes, struktur dan agensi harus dipandang sebagai dualitas (duality), dua sisi dari satu mata uang yang sama. Hubungan antara keduanya bersifat dialektika, dalam arti struktur dan agensi saling mempengaruhi dan hal ini berlangsung terus-menerus.

Struktur mempengaruhi agensi dalam dua arti: memampukan (enabling) dan menghambat (constraining). Giddens mengambil contoh bahasa yang harus dipelajari dengan susah-payah, baik kosa kata maupun tatabahasanya. Akan tetapi dengan menguasai kosa kata dan tatabahasa, orang mampu untuk berkomunikasi dengan lawan bicaranya tanpa batasan. Dalam hal ini struktur justru

${ }^{6}$ Anthony Giddens. The Constitution of Society. Cambridge: Polity Press, 1984, hlm. 21-22.

${ }^{7}$ Ibid., hlm. 9. 
memampukan agensi, jika ia tidak pernah mempelajari kosa kata berikut tatabahasa akan tetap bisu. Pengertian struktur disini sama sekali lain dari yang dikemukakan oleh Levi-Strauss; bahkan dalam pengertian Giddens -struktur sekaligus juga medium.

Hubungan struktur dan agensi menjadi tambah rumit jika diingat bahwa agensi juga dapat mempengaruhi struktur. Agensi dapat meninggalkan struktur, tidak selalu tunduk kepada struktur. Ia dapat mencari kesempatan maupun kemungkinan untuk keluar dari peraturan dan ketentuan yang ada. Oleh karena itu, dalam teori strukturasi yang menjadi pusat perhatian bukan struktur, bukan pula agensi, melainkan yang disebut "social practice". Memang orang tidak boleh melupakan struktur dan juga agensi, bahkan seharusnya memahami secara detail struktur dan juga agensi. Akan tetapi fokus utama harus diletakkan pada social practice, yaitu bagaimana manusia-manusia menjalani hidup sehari-hari.

$\begin{array}{ll}\text { Civil rights } & \text { Surveillance as policing. } \\ \text { Political rights } & \begin{array}{l}\text { Surveillance as reflexive monitoring } \\ \text { of state administrative power }\end{array} \\ \text { Economic rights } & \begin{array}{l}\text { Surveillance as "management" of } \\ \text { production. }\end{array}\end{array}$

Hubungan "negara" dan "masyarakat" adalah social practice juga, jika "negara" dipahami sebagai struktur dan "masyarakat" sebagai agensi. Hal ini jelas digambarkan dalam pembahasan tentang "class, sovereignty and citizenship". ${ }^{8}$ Giddens menjelaskan terjadinya the dialectic of control dalam masyarakat dengan sistem pengawasan (surveillance) ini dapat menyebabkan pihak yang diperintah untuk mempengaruhi pihak yang memerintah -yang disebut gejala tawar-menawar, bahkan konflik. Ia menegaskan bahwa konflik ini muncul di seputar citizen rights yang dapat diuraikan atas tiga hak: hak sipil, hak politik, dan hak ekonomi. Oleh karena itu, Giddens menyebutkan tiga arena kontestasi atau konflik. Hak sipil diperjuangkan di dalam gedung parlemen, hak politik diperjuangkan dalam pemilu, dan hak ekonomi dalam pabrik.

Kontestasi dalam reklamasi Teluk Benoa melibatkan koalisi masyarakat adat bersama ForBALI sebagai agensi berhadapan dengan investor PT TWBI di satu pihak dan pemerintah di lain pihak. Pada perkembangannya isu reklamasi Teluk Benoa melampaui isu lingkungan dan telah merambah ke ranah politik lokal. Ketika Pilgub Bali, Pilwakot Denpasar dan Pilbup Badung memaksa semua kandidat membuat pakta integritas menolak reklamasi Teluk Benoa. Isu reklamasi Teluk Benoa ini telah menjadi preferensi elektabilitas bagi pejabat publik di Bali, bahkan keterpilihan Bandesa (pejabat desa adat).

Pihak investor PT Tirta Wahana Bali Internasional (TWBI) berencana melakukan reklamasi di Teluk Benoa Bali. Bentang ruang Teluk Benoa terletak di perairan lintas Kota Denpasar dan Kabupaten Badung, sebagian termasuk dalam Kecamatan Denpasar Selatan, Kuta dan Kuta Selatan. Bentang ruang Teluk Benoa dikelilingi 6 kelurahan di Kota Denpasar dan 6 desa di Kabupaten Badung. Luas perairan 1.988,1 hektar dibagi 3 zona, yakni: Zona 1 (dermaga Pelabuhan Benoa \& Tanjung Benoa) seluas 1.668,3 hektar; Zona 2 (Pelabuhan Benoa dan Pulau Serangan) seluas 231,3 hektar; dan Zona 3 (Suwung Kangin dan Pulau Serangan) seluas 88,5 hektar.

${ }^{8}$ Anthony Giddens. The Nation-State and Violance. Cambridge: Polity Press, 1985, Bab 8. 


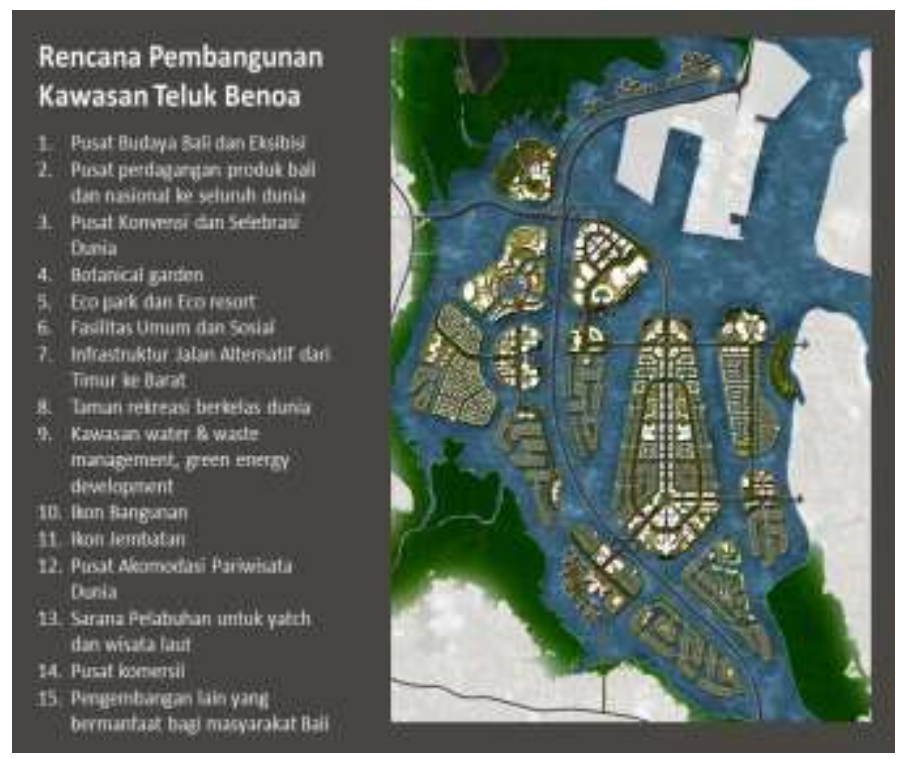

\section{Gambar 1. Konstruksi Wacana oleh PT WTBI}

Sumber: Presentasi Perusahaan

\section{Kontra Wacana}

Representasi aktor resistensi adalah forum rakyat Bali tolak reklamasi (ForBALI) merupakan gerakan masyarakat sipil Bali yang menolak keras rencana investor PT TWBI (Tirta Wahana Bali Internasional) untuk membangun 12 pulau baru dengan cara pengurugan seluas 700 hektar di kawasan Teluk Benoa, Bali Selatan. Direncanakan di pulau buatan ini akan dibangun fasilitas hiburan sekelas Disneyland, Art Center, lapangan golf, Mall megah dan hotel-hotel mewah berbintang. ForBALI lahir dari inisiatif kaum muda Bali yang beranekaragam baik suku, agama, golongan dan profesi. Semangat yang menjadi dasar ForBALI adalah: Kepedulian dan rasa sayang akan Bali!

ForBALI adalah forum non partisan dan independen, tidak ada niat menurunkan Gubernur, maupun bertindak anarkis, melainkan masyarakat sipil yang cinta damai namun peduli dan sayang Bali. ForBALI tidak anti pembangunan dan tidak anti pariwisata. Forum ini sangat mendukung pembangunan pariwisata di Bali selama proses pembangunan tersebut tidak menghancurkan masa depan alam, lingkungan dan adatistiadat di Bali, bersih dari korupsi dan aksi kongkalikong penguasa dan pengusaha, serta taat pada hukum dan memenuhi rasa keadilan bagi masyarakat luas. ${ }^{9}$

Apa arti penting sikap "Tolak Reklamasi” bagi masyarakat Bali? Rencana investor untuk melakukan reklamasi, revitalisasi, urug laut atau apapun istilahnya di Teluk Benoa seluas 700 hektar hanya akan menguntungkan segelintir pihak yaitu Pengusaha dan kroni-kroninya. Bali sudah kekurangan air bersih. Bayangkan setiap hari, air yang keluar terus mengecil dan PDAM mulai kesulitan memasok kebutuhan air ke masyarakat luas. Jika reklamasi jadi dilaksanakan maka pulau baru itu akan mengambil jatah air bersih. Tempat pembuangan sampah di Denpasar sudah terlalu

${ }^{9}$ ForBALI Surat Kabar Edisi 1 Tahun 2014. "Apa itu Bali Tolak Reklamasi?" 
penuh, bau busuk terus tercium hari ke hari semakin luas wilayahnya. Ini contoh sebagian kecil dari potensi dampak lingkungan jika kita membiarkan reklamasi terjadi.

Tambahan lagi ancaman banjir di daerah Bali selatan akibat luberan air saat laut pasang. Rumah-rumah di pesisir Bali selatan akan menjadi langganan banjir rob setiap harinya. Orang-orang yang menggantungkan hidup dari laut akan kehilangan pekerjaannya karena arus air berubah. Sehubungan dengan itu, gerakan tolak reklamasi Teluk Benoa menjadi penting untuk menyelamatkan rakyat Bali dan wilayah pesisir Bali dari kehancuran yang lebih besar akibat kerakusan pengusaha dan penguasa. Kesadaran publik terbentuk bahwa mendiamkan atau meloloskan rencana Gubernur dan Investor untuk mereklamasi Teluk Benoa berarti sama dengan membiarkan masa depan Bali hancur.

Konsep perjuangan dalam hal ini dimaksudkan setara dengan perlawanan (resistance) yang mengacu pada pengertian yang dibangun oleh Turner dan Caoutte (2009: 9) dalam studi mereka tentang perlawanan petani di Asia Tenggara. Bagi mereka, pertama-tama perlawanan harus dimaknai dari pemahaman tentang kekuasaan. Kekuasaan, bagi mereka, adalah permainan relasional antara yang dominan dan yang tersubordinasi. Mereka membangun pengertian perlawanan dengan berangkat dari pemikiran tiga teoretikus, yakni Antonio Gramsci, Karl Polanyi, dan James C. Scott.

Bagi Gramsci, kelas penguasa memanipulasi sistem sosial dan moral masyarakat sehingga kapitalisme menjadi cara pandang bersama. Inilah proses pembentukan hegemoni. Artinya, hegemoni bekerja dengan menjaga keseimbangan antara paksaan dan persetujuan. Proses pemaksaan tidaklah terlalu melampaui proses persetujuan. ${ }^{10}$ Perlawanan, dengan demikian, adalah proses menyingkap hegemoni -yang disebut oleh Gramsci sebagai hegemoni tanding (counterhegemony). Dalam konteks buruh di Italia, perlawanan adalah penaklukan negara, yang dapat dicapai dengan mengganti kelas dominan yang memiliki fungsi penting dalam tatanan masyarakat. Langkah pertama menuju tahap ini dalam perjuangan buruh ialah dengan merebut pabrik. Modal hegemoni tanding sangat beraneka-ragam dari "perang ... hingga boikot". ${ }^{11}$

Transformasi besar (the great transformation), bagi Polanyi (2001 [1944]), merujuk pada krisis kapitalisme ketika pasar mengambil peran terlalu banyak. Fungsi ekonomi seharusnya bagian dari fungsi sosial, bukan mendominasi fungsi sosial. Krisis bermula ketika berlaku pembagian masyarakat ke dalam marka ekonomi dan politik. Model susunan masyarakat seperti ini hanya berfungsi, hanya jika keseluruhan masyarakat sudah tunduk pada logika ekonomi. Dominasi logika ekonomi ini menyebabkan munculnya komoditas fiktif seperti buruh, tanah, dan uang. Perlawanan, yang dalam istilah Polanyi disebut sebagai gerakan tanding (counter-movement), adalah tanggapan terhadap proses komodifikasi.

Scott (1990) memunculkan suatu bentuk perlawanan yang berbeda. Ia menjelaskan bagaimana kekuasaan bekerja dalam proses subordinasi di berbagai kasus seperti perbudakan dan kasta. Bagi Scott, kelompok dominan tidak pernah sepenuhnya mampu mengambil kontrol dalam panggung kekuasaan. Selalu ada perlawanan. Baginya, ada jua jenis perlawanan. Pertama, perlawanan yang cenderung tertutup, yang dianggap sebagai komponen dari politik yang tak tampak (infrapolitics). Politik yang tak tampak pada dasarnya menantang kekuasaan secara tertutup,

${ }^{10}$ Gramsci, Anthonio. 2000. The Gramsci Reader: Selected Writinfs 1916-1935. D. Forgacs (Ed.). New York: New York University Press, hlm. 261.

${ }^{11}$ Turner dan Caoutte. 2009. "Shifting Fields of Rural Resistance in Southeast Asia". Dalam Agrarian Angst and Rural Resistance in Contemporary Southeast Asia, D. Caoutte dan S. Turner (Ed.). London dan New York: Taylor \& Francis, hlm. 10 
misalnya perlawanan sehari-hari atau akrab dikenal sebagai perlawanan Scottian. Kedua, perlawanan terbuka yang juga sangat luas bentuknya, mulai dari petisi, demonstrasi, hingga revolusi. ${ }^{12}$

Pada kasus ForBALI perlawanan dilakukan secara terbuka dengan aksi-aksi pemasangan spanduk "Tolak Reklamasi", demonstrasi dan gelar seni di lapangan Renon maupun gelar hukum di persidangan pengadilan. Perlawanan ini digerakkan bersama total 39 desa adat dengan ForBALI berawal 50an hingga sekarang menyentuh ratusan ribu massa di bawah koordinasi I Wayan "Gendo" Suardana. Masyarakat adat membangun argumentasi bahwa Teluk Benoa adalah kawasan suci berdasarkan Pesamuhan Sabha Pandita PHDI (Parisada Hindu Dharma Indonesia), karena merupakan tapak masuknya pengembangan Hindu di Bali dengan ditandai keberadaan 70 pura dan daratan pasang-surut (muntig-muntig).

Coastal Grabing merupakan fenomena perampasan wilayah pesisir dari common property menjadi milik privat dengan alih-alih pembangunan. Pemanfaatan kawasan konservasi untuk fasilitas publik di perairan Teluk Benoa, seperti pembangunan Pelabuhan Benoa, Bandara Ngurah Rai, dan Tol Bali Mandara dapat diterima oleh masyarakat. Akan tetapi, keberatan terhadap reklamasi Pulau Serangan yang berdampak pada kerusakan lingkungan praktis dapat diredam di bawah tekanan rezim Orde Baru.

Sekarang ini masyarakat Bali menghadapi ancaman perampasan ruang dengan proyek reklamasi Teluk Benoa yang dilakukan investor swasta dengan fasilitasi pemerintah. Bagi pemerintah yang terjadi adalah kapitalisasi ekologis, dengan memanfaatkan lahan perairan untuk pembangunan fasilitas pariwisata yang mendorong percepatan pertumbuhan ekonomi. Akan tetapi, dampak ekologis dan sosial-budaya yang selama ini menjadi kekhawatiran masyarakat perlu dikaji lebih lanjut untuk menghindarkan kerusakan lingkungan yang lebih besar dan berbagai dampak yang menyertainya.

${ }^{12}$ Scott, J.C. 1990. Domination and the Arts of Resistance: Hidden Transcript. New Haven and London: Yale University Press. 


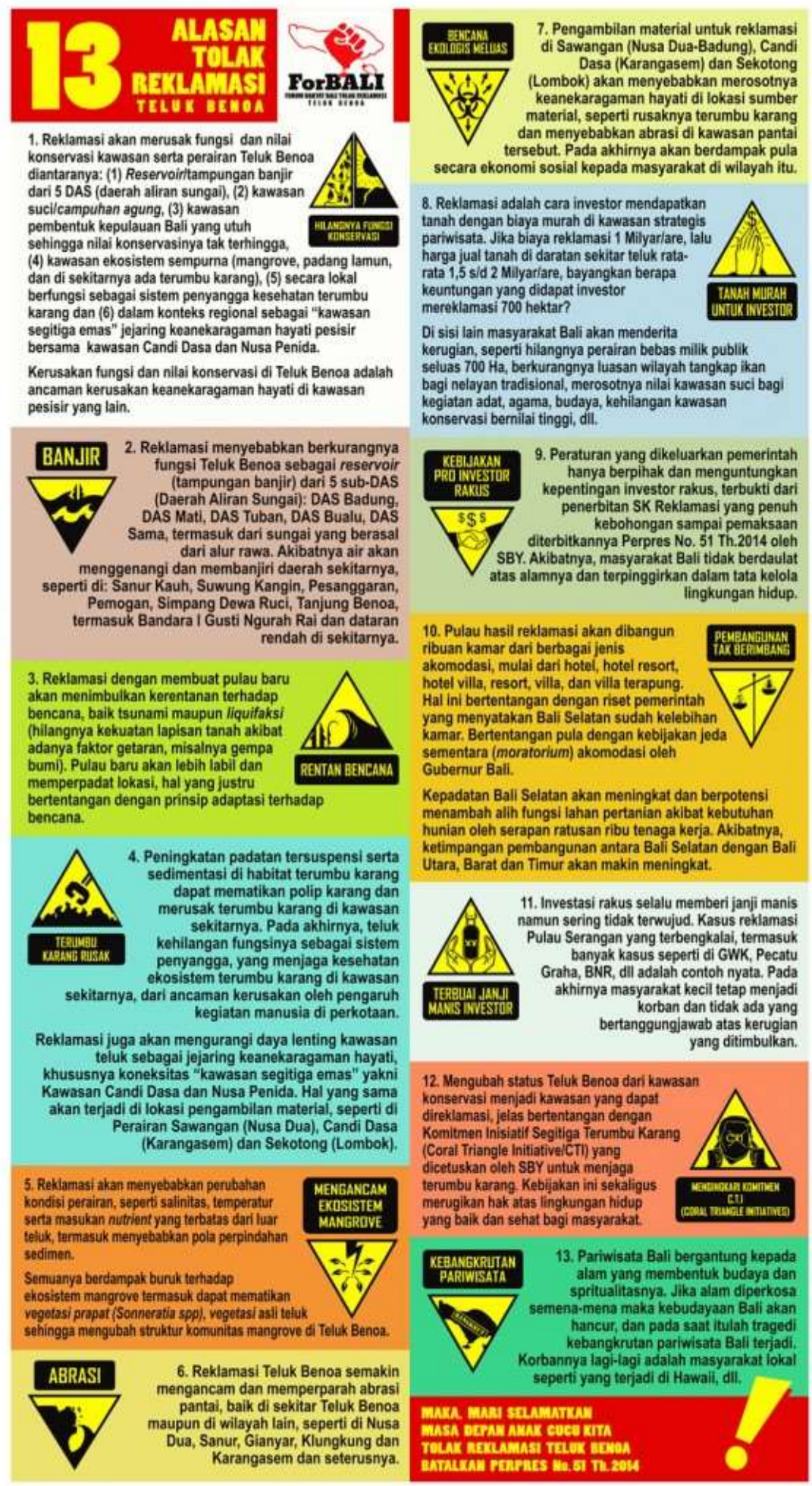

Gambar 2. Kontra Wacana dari ForBALI

Sumber: https://www.forbali.org/id/13-alasan-tolak-reklamasi-teluk-benoa/ 
Baru-baru ini, penelitian dalam lingkup hidrologi dilakukan oleh Ulung J. Wisha dkk (2017) tentang "Current movement in Benoa Bay water, Bali, Indonesia: Pattern of tidal current changes simulated for the condition before, during, and after reclamation." Disimpulkan bahwa pola hidrodinamik stabil selama simulasi 1995, namun mengalami penurunan dalam simulasi untuk 2016 dan 2018 saat reklamasi diimplementasikan. Dalam simulasi 2016, pengembangan pulau Serangan dan Pelabuhan Benoa merupakan faktor utama yang mengganggu aliran arus di sekitar teluk. Kondisi masa depan diprediksi dengan model numerik dikombinasikan dengan prakiraan. Kecepatan arus berkurang drastis dibandingkan dengan simulasi sebelumnya. Kondisi ini akan mempengaruhi pola hidro-dinamika. Di satu sisi, reklamasi niscaya meningkatkan aktivitas pariwisata yang meningkatkan pendapatan daerah. Akan tetapi, di sisi lain reklamasi menyebabkan penurunan mekanisme transport sedimen yang secara langsung menghambat siklus biogeokimia dan mempengaruhi kemampuan bertahan biota. Disarankan agar peneliti lain yang tertarik dengan isu ini melakukan survei terhadap pengukuran dan air pasang yang ada. Penelitian komprehensif semacam itu perlu dilakukan agar bermanfaat bagi berbagai pemangku kepentingan, yaitu pemerintah, masyarakat, dan juga pengembang. Hal itu dapat dilakukan dengan sukses jika pihak-pihak tersebut mempertimbangkan secara bijaksana dampak reklamasi di teluk Benoa. ${ }^{13}$.

Akhirnya, kajian Agung Wardana "Neoliberalisasi Kawasan Perairan Teluk Benoa: Sebuah Catatan Kritis atas Praksis Perlawanan di Bali" menyimpulkan bahwa PT TWBI sebagai korporasi mencoba menampilkan wajah kemanusiaan dengan mengklaim bahwa proyeknya dimaksudkan untuk mitigasi risiko bencana tsunami, juga wajah konservasi melalui pemeliharaan hutan bakau dan pembuatan ruang terbuka hijau. Kaburnya posisi PT TWBI sebagai institusi publik atau swasta dengan mudah teridentifikasi. Pada satu sisi, PT TWBI merupakan lembaga dengan tujuan utama kesejahteraan para pemilik saham; dan pada lain sisi, akibat terfragmentasinya institusi negara, PT TWBI juga muncul layaknya institusi publik yang menjawab kebutuhan sosial masyarakat, meskipun bersifat sangat tersegmentasi. Konsekuensinya, perlawanan atas kapitalisme model neoliberal saat ini dihadapkan pada realitas yang kompleks. Perlawanan tanpa disertai dengan bacaan yang lebih jernih atas kerja kapitalisme neoliberal saat ini akan dengan mudah diserap, diakomodasi, serta dijadikan justifikasi oleh kapitalisme itu sendiri. Oleh karena itu, sudah saatnya gerakan lingkungan dan gerakan sosial lainnya di Indonesia mengartikulasikan kritik dan negasi atas kapitalisme dan negara secara lebih tegas dalam kerja-kerja advokasinya agar tidak kehilangan relevansinya dalam transformasi sosial yang lebih adil. ${ }^{14}$

\section{Purna Wacana}

Berdasarkan pembahasan tersebut di atas dapat dipetakan sejumlah isu besar, yang dapat ditarik ke ranah reklamasi Teluk Benoa Bali. Pertama, ketidaksesuaian nilai-nilai Ekonomi Politik yang dianut mendukung eksploitasi sumberdaya alam dan perusakan lingkungan (Neo-Liberalisme).

${ }^{13}$ https://doi.org/10.1016/j.rsma.2017.10.006

${ }^{14}$ Wardana, Agung. "Neoliberalisasi Kawasan Perairan Teluk Benoa: Sebuah Catatan Kritis atas Praksis Perlawanan di Bali" dalam Ekologi Politis Air: Akses, Eksklusi, dan Resistensi. Wacana Jurnal Transformasi Sosial Nomor 35/Tahun XIX/2017. 
Perkembangan investasi global mempengaruhi sistem penguasaan sumberdaya. UUD 1945 pasal 33 ayat 3 menyatakan bahwa: "Bumi, air, dan kekayaan alam yang terkandung di dalamnya dikuasai oleh negara dan digunakan sebesar-besarnya kemakmuran rakyat." Amanat konstitusi agar penggunaan lahan pesisir diarahkan untuk memberikan manfaat ekonomi dan sosial bagi masyarakat pesisir, bukan mengekploitasi sumber daya pesisir demi meraih keuntungan pribadi.

Kedua, kelemahan birokrasi untuk lepas dari kepentingan politik membuat pembaruan kebijakan yang mendasar tidak terwujud. Ketiga, peningkatan kejadian banyak bencana alam maupun kerusakan lingkungan yang menimbulkan banyak korban. Akan tetapi, itu pun tidak mendorong keputusan-keputusan politik yang mampu mengarah pada pembaruan kebijakan.

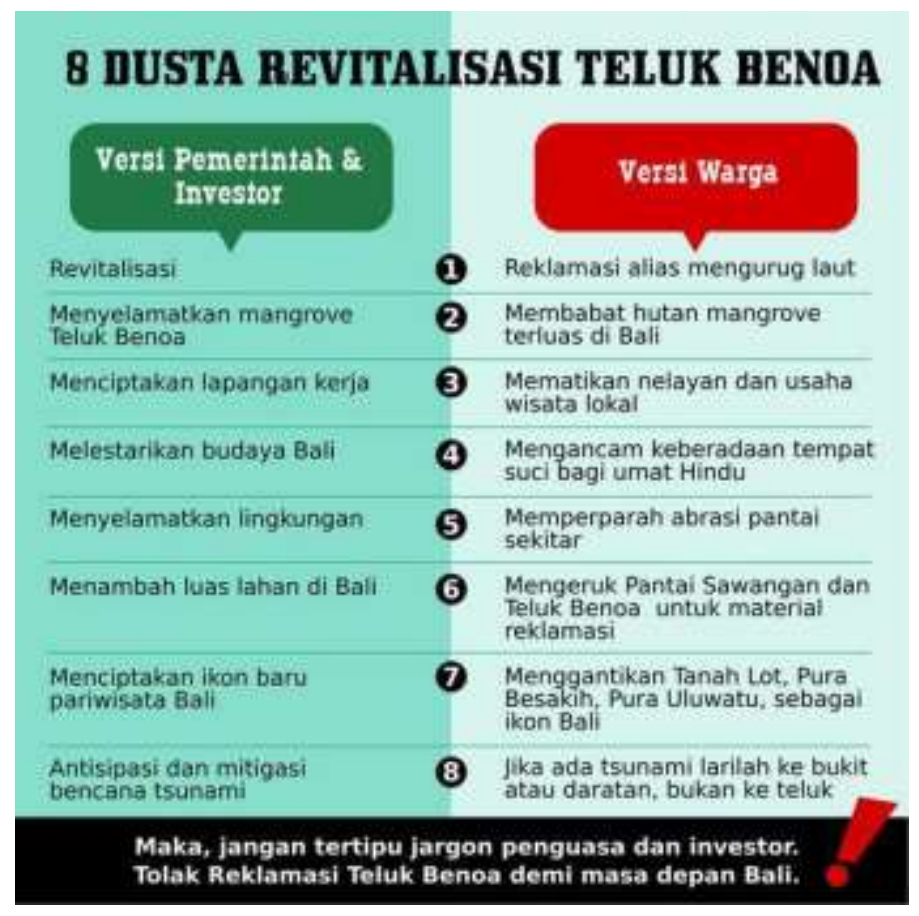

Gambar 3. Mengkritisi "Revitalisasi" Teluk Benoa

Sumber: https://www.kaskus.co.id/thread/5416a20298e31b412b8b456d/ kronologis-tolakreklamasi-teluk-benoa-by-forbali13/

Perjuangan masyarakat sipil untuk mempertahankan wilayah konservasi Teluk Benoa dapat dikatakan sebagai penjelmaan penalaran publik yang kritis. Gerakan ini menunjukkan bagaimana partisipasi publik penting dalam menjaga alam Indonesia yang kerap berada dalam kondisi terancam (Putri, 2016). ${ }^{15}$ Terdapat tiga argumen utama mengapa reklamasi ditolak oleh masyarakat Bali. Pertama menyangkut keragaman hayati wilayah hutan Mangrove, Teluk Benoa merupakan penopang berbagai kehidupan spesies, padang lamun dan terumbung karang. Kedua, dari sisi Budaya dan Religi, Teluk Benoa merupakan kawasan suci yang menyimpan sejarah terbentuknya agama dan adat Hindu Siwa di Bali. Ketiga dari perspektif Ekonomi, Teluk Benoa merupakan lokasi

${ }^{15}$ https://sarasdewiblog.wordpress.com/2016/11/29/reklamasi-teluk-benoa-dan-problem-ketidakadilanekologis/ 
penting yang menyangga kesehatan pesisir Bali Selatan, yang sebagian besar berprofesi sebagai nelayan dan wisata bahari.

Perkembangan terbaru kontroversi proyek reklamasi Teluk Benoa berakhir setelah Pemerintah melalui Kementerian Kelautan dan Perikanan tidak memberikan perpanjangan izin lokasi yang telah kedaluarsa sejak 26 Agustus 2018. Analisis mengenai dampak lingkungan (Amdal) proyek reklamasi Teluk Benoa dinilai tidak layak karena aspek sosio kultural yaitu adanya penolakan dari masyarakat (Gumilang, 2018). ${ }^{16}$ Aspirasi masyarakat sebagaimana yang diperjuangkan oleh gerakan ForBALI telah diakomodasi oleh Negara, dengan demikian rakyat Bali memenangkan perjuangan yang dilakukan selama lima tahun berhadapan dengan pihak swasta PT TWBI selaku investor.

Kabar dibatalkannya proyek reklamasi Teluk Benoa sementara waktu membuat masyarakat Bali khususnya bernafas lega, karena keberhasilan usahanya untuk menghindarkan ekosistem Teluk Benoa dari ancaman kerusakan lingkungan hidup atas nama pembangunan. Dalam kerangka strukturasi, Negara sebagai struktur maupun arena kontestasi dari agensi kelompok-kelompok kepentingan secara dialektis menjalankan pembangunan berwawasan lingkungan, sehubungan dengan itu diperlukan peta jalan sistem pengelolaan sumberdaya alam serta lingkungan hidup yang berkeadilan dan berkelanjutan.

Perkembangan terkini menunjukkan, di satu pihak PT TWBI setelah 2 kali 2 tahun ijin lokasi habis masa berlakunya pada 26 Agustus 2018. Investor ini mengantongi lagiizin lokasi reklamasi No. B-795/Men-KP/Xi/2018 dari Menteri Kelautan dan Perikanan yang diterbitkan 29 November 2018, sehingga berproses untuk mempersiapkan kembali proyek reklamasi Teluk Benoa. Sementara di lain pihak, ForBALI setelah mendeklarasikan kemenangannya fase I karena berakhirnya ijin lokasi 2018 dan investor belum memenuhi aspek sosial-budaya dari studi kelayakan.

Sekarang ini, gerakan ForBALI yang menjadi mandataris Pasubayan Pakraman sedang mempersiapkan energi untuk memasuki babak baru upaya menggagalkan reklamasi Teluk Benoa. Agenda ForBALI ke depan, pertama: mendorong hasil kajian AMDAL tidak layak secara sosialbudaya. Kedua, mengajukan review terhadap Perpres No. 51/2014 yang menjadi "biang-kerok" wacana reklamasi Teluk Benoa. Ketiga, mendorong pembatalan Perpres No. 51/2014 untuk mengakhiri polemik reklamasi Teluk Benoa. ${ }^{17}$

Akhirnya, kita masih akan menyaksikan upaya perampasan pesisir Teluk Benoa belum berakhir, dan perjuangan masyarakat adat bersama ForBALIuntuk keadilan ekologis di Teluk Benoa sedang mulai babak baru ...

\section{Daftar Pustaka}

ForBALI Surat Kabar Edisi 1 Tahun 2014. “Apa itu Bali Tolak Reklamasi?”

ForBALI. "Mengapa Kami Menolak Reklamasi Teluk Benoa Bali”. URL $=<$ http://www.forbali.org/id/mengapa-kami-menolak>

${ }^{16}$ Gumilang, Prima. "Reklamasi Teluk Benoa Disetop Berkat Penolakan Warga Bali" $\mathrm{URL}=<$ https://www.cnnindonesia.com/nasional/20180828082316-20-325397/reklamasi-teluk-benoadisetop-berkat-penolakan-warga-bali>

${ }^{17}$ Wawancara penulis dengan I Wayan Gendo Suardana (Koordinator ForBALI) di Sekretariat Walhi Eksekutif Daerah Bali pada 14 Februari 2019. 
Giddens, Anthony. 1984. The Constitution of Society. Cambridge: Polity Press. , 1985. The Nation-State and Violance. Cambridge: Polity Press.

Gramsci, A. 2000. The Gramsci Reader: Selected Writinfs 1916-1935. D. Forgacs (Ed.). New York: New York University Press.

Gubernur Bali. Keputusan Gubernur Bali Nomor 2138/02-C/HK/2012 tentang Pemberian Izin dan Hak Pemanfaatan, Pengembangan dan Pengelolaan Wulayah Perairan Teluk Benoa Provinsi Bali.

Gubernur Bali. Keputusan Gubernur Bali Nomor 1727/01-B/HK/2013 tentang Izin Studi Kelayakan Rencana Pemanfaatan, Pengembangan dan Pengelolaan Wilayah Perarairan Teluk Benoa.

Gumilang, Prima. "Reklamasi Teluk Benoa Disetop Berkat Penolakan Warga Bali" URL=<https://www.cnnindonesia.com/nasional/20180828082316-20-325397/reklamasiteluk-benoa-disetop-berkat-penolakan-warga-bali>

Hands Off the Land Alliance. The Global Water Grab. March 2014.

Kartodirjo, Hariadi., Hira Jhamtani (ed.). (2006). Politik Lingkungan dan Kekuasaan di Indonesia. Jakarta: PT Equinox Publishing Indonesia.

Keputusan Pesamuhan Sabha Pandita Parisada Hindu Dharma Indonesia Nomor. 1/Kep/SP PARISADA/IV/2016 tentang Kawasan Suci Teluk Benoa.

Kementerian Kelautan dan Perikanan Republik Indonesia. Izin Lokasi Reklamasi (Badan Usaha) Nomor 445/Men-KP/VIII/2014.

Kementerian Kelautan dan Perikanan Republik Indonesia. Izin Lokasi Reklamasi (Badan Usaha) Nomor B-795/Men-KP/XI/2018.

Kementerian Koordinator Bidang Perekonomian. 2013. "Koridor Ekonomi Bali dan Nusa Tenggara memiliki tema pembangunan sebagai Pintu Gerbang Pariwisata dan Pendukung Pangan Nasional" Bab 5. Perkembangan Pelaksanaan MP3EI Koridor Ekonomi Bali dan Nusa Tengara dalam Laporan Perkembangan Pelaksanaan MP3EI.

Lembaran Negara Republik Indonesia Tahun 2009 Nomor 140. Undang Undang Nomor 32 Tahun 2009 Tentang Perlindungan dan Pengelolaan Lingkungan Hidup.

Lembaran Negara Republik Indonesia Tahun 2011. Peraturan Presiden Republik Indonesia Nomor 32 Tahun 2011 Tentang Masterplan Percepatan dan Perluasan Pembangunan Ekonomi Indonesia 2011-2025.

Lembaran Negara Republik Indonesia Tahun 2011. Peraturan Presiden Republik Indonesia Nomor 45 Tahun 2011 Tentang Rencana Tata Ruang Kawasan Perkotaan Denpasar, Badung, Gianyar, dan Tabanan.

Lembaran Negara Republik Indonesia Tahun 2012 Nomor 267. Peraturan Presiden Republik Indonesia Nomor 122 Tahun 2012 Tentang Reklamasi Wilayah Pesisir dan Pulau-pulau Kecil.

Lembaran Negara Republik Indonesia Tahun 2014 Nomor 121. Peraturan Presiden Republik Indonesia Nomor 51 tahun 2014 Tentang Perubahan atas Peraturan Presiden Nomor 45 Tahun 2011 tentang Rencana Tata Ruang Kawasan Perkotaan Denpasar, Badung, Gianyar, dan Tabanan.

Putri, Saraswati. "Reklamasi Teluk Benoa dan Problem Ketidakadilan Ekologis". URL=<https://sarasdewiblog.wordpress.com/2016/11/29/reklamasi-teluk-benoa-danproblem-ketidakadilan-ekologis/>

“Reklamasi Perparah Degradasi Lingkungan” dalam KOMPAS, Selasa 20 Maret 2018. 
Scott, J.C. 1990. Domination and the Arts of Resistance: Hidden Transcript. New Haven and London: Yale University Press.

Suardana, I Wayan Gendo. "Menguak Misteri SK Reklamasi Jilid 2". URL=<https://gendovara.com/menguak-misteri-sk-reklamasi-jilid-2/>

$$
\text { "Panggilan Aksi BTR", } 16 \text { Juni 2019. URL= }
$$
$<$ https://www.facebook.com/gendo.suardana?_tn__ $=\% 2 \mathrm{CdC}-\mathrm{R}-\mathrm{R} \& \mathrm{eid}=\quad$ ARCL5zcVsK1KSbiHsuinPZCLIoWYKuDKQhjU_M9ZiTQcvlSI-pVq0ZOC pa7RZ03CYMRISyRCsDtButs\&hc_ref=ARRgp0Uy9jMnWE544w1Z1SPMp1tF433ilxSwRiWOFK7M2KJEZa 0T94n4RNSzue3TGE\&fref=nf>

Suadiarta, Ketut, I Gedhe Hendrawan, Ketut Sarjana Putra, dan I Made Iwan Dewantama. Kajian Modeling Dampak Perubahan Fungsi Teluk Benoa untuk Sistem Pendukung Keputusan (Decision Support System) dalam Jejaring KKP Bali. Laporan Ringkasan Eksekutif Conservation International Indonesia.

Tambahan Lembaran Negara Republik Indonesia Tahun 2007 Nomor 4739. Undang Undang Republik Indonesia Nomor 27 Tahun 2007 Tentang Pengelolaan Wilayah Pesisir dan Pulaupulau Kecil.

Tirta Wahana Bali Internasional. URL=<twbi.co.id/index.php?page=concept $>$

TNI Agrarian Justice Progamme. The Global Ocean Grab. Masifundise and Afrika Kontakt September 2014.

Turner, S., D. Caoutte. 2009. "Shifting Fields of Rural Resistance in Southeast Asia". Dalam Agrarian Angst and Rural Resistance in Contemporary Southeast Asia, D. Caoutte dan S. Turner (Ed.). London dan New York: Taylor \& Francis e-Library.

WALHI Tinjauan Lingkungan Hidup 2018. Masa Depan Keadilan Ekologis di Tahun Politik.

WALHI Februari 2013. Perampasan Lahan dan Krisis Pangan.

WALHI Bali. "Kronologis Inkonsistensi Gubernur Bali dalam Kasus Reklamasi di Teluk Benoa".

Wardana, Agung. "Neoliberalisasi Kawasan Perairan Teluk Benoa: Sebuah Catatan Kritis atas Praksis Perlawanan di Bali" dalam Ekologi Politis Air: Akses, Eksklusi, dan Resistensi. WacanaJurnal Transformasi Sosial Nomor 35/Tahun XIX/2017.

Wisha U.J., Try Al Tanto, Widodo S. Pranowo, Semeidi Husrin. "Current movement in Benoa Bay water, Bali, Indonesia: Pattern of tidal current changes simulated for the condition before, during, and after reclamation." Regional Studies in Marine Science (2017), URL= <https://doi.org/10.1016/j.rsma.2017.10.006.> 